RHINOLOGY

\title{
Effectiveness of endoscopic septoplasty in different types of nasal septal deformities: our experience with NOSE evaluation
}

\author{
Efficacia della settoplastica endoscopica nei vari tipi di deformità settale: \\ la nostra esperienza con il questionario NOSE \\ G. Dell'Aversana Orabona', A. Romano'1, V. Abbate', G. Salzano', P. Piombino ${ }^{2 *}$, \\ F. Farina ${ }^{3}$, A. Pansini', G. laconetta ${ }^{4}$, L. Califano ${ }^{1}$ \\ ${ }^{1}$ Department of Maxillofacial Surgery, University of Naples Federico II, Naples, Italy; ${ }^{2}$ Department of Otorhinolaryngology, \\ University of Naples SUN, Naples, Italy; ${ }^{3}$ Department of Economy and Business, University of Sannio, Benevento, Italy; \\ ${ }^{4}$ Department of Neurosurgery, University of Salerno, Italy \\ "Present address: Department of Otorhinolaryngology, University Luigi Vanvitelli of Naples, Italy
}

\section{SUMMARY}

Septal deviations are the most frequent cause of nasal obstruction, and represent a common complaint in rhinologic practice. Since the first description of Lanza et al. in 1991, the use of the endoscope for the correction of septal deformities is increasingly more frequent. The purpose of this study is to evaluate the effectivenes of the endoscopic septoplasty for the correction of each of the 7 types of septal deformities according to the Mladina's classification. A retrospective chart review was performed in 59 consecutive patients presenting to our Department for Endoscopic Septoplasty from February 2012 to August 2014. For each deviation, descriptive statistics (mean and standard deviation, significant increase/decrease) was used to asses the corrective capacity and time-dependent effects at follow-up. This study shows that the corrective power of endoscopic septoplasty is different according to the type of deviation. To our knowledge this is the first study that evaluates the corrective capacity of this technique for each deviation by analysing pre- and postoperative objective outcomes as well as subjective outcomes gathered from the validated NOSE questionnaire. Even if endoscopic septoplasty may now be considered a reliable alternative to the classic technique, it is essential to identify the right deformity preoperatively in order to provide the correct therapeutic choice.

KEY WORDS: Endoscopic septoplasty • Septal deviation • NOSE scale • Septal deformities • Cottle‘s area

\section{RIASSUNTO}

Le deviazioni del setto sono la causa più frequente di ostruzione nasale e rappresentano un problema comune nella pratica rinologica. L'uso dell'endoscopio per la correzione delle deformità del setto dalla prima descrizione di Lanza et al. nel 1991 ad oggi è sempre più frequente. Lo scopo di questo studio è quello di valutare l'efficacia della settoplastica endoscopica per la correzione di ciascuno dei 7 tipi di deformità del setto secondo la classificazione di Mladina. Una revisione retrospettiva è stata eseguita in 59 pazienti che si sono presentati presso il nostro Dipartimento per essere sottoposti a settoplastica endoscopica da febbraio 2012 ad agosto 2014. Perogni deviazione, è stata effettuata un'analisi statistica descrittiva (media e deviazione standard, aumento/diminuzione significativa) al fine di valutare la capacità correttiva e gli effetti al follow-up. Questo studio ha dimostrato che il potere correttivo della settoplastica endoscopica è diverso a seconda del tipo di deviazione. Questo è il primo studio che valuta la capacità di correzione di questa tecnica per ogni deviazione, analizzando i risultati oggettivi pre e post-operatori, nonché gli esiti soggettivi raccolti dal questionario NOSE. Anche se la settoplastica endoscopica può essere considerato ora una alternativa affidabile alla la tecnica classica è essenziale identificare preoperatoriamente il tipo di deformità al fine di fornire la corretta scelta terapeutica.

PAROLE CHIAVE: Settoplastica endoscopica $\bullet$ Deviazione settale $\bullet$ NOSE scale $\bullet$ Deformità settale $\bullet$ Area di Cottle 


\section{Introduction}

Septal deviations are the most common cause of nasal obstruction, representing a common compliant in rhinologic practice. Since its introduction, procedures for correction of nasal septal deformities have undergone several modifications, from radical septal resection, to possible preservation of septal framework and nasal mucosa. Frequently, septal deformities can be associated with lateral wall diseases or may be the cause of them. A significantly deviated nasal septum has been implicated in epistaxis, sinusitis, obstructive sleep apnoea and headaches attributable to contact point with structures of lateral nasal wall ${ }^{1}$.

For this reason, correction of septal deformities cannot be separated from treatment of disorders of the lateral wall when present. Thus, endoscopic septoplasty is a useful technique for treating symptomatic deformities, but also for improving intraoperative surgical access to lateral nasal wall surgeries (e.g. dacryocystorhinostomy, functional endoscopic sinus surgery) ${ }^{23}$.

Since the first description by Lanza et al. in 1991, the use of the endoscope for the correction of septal deformities is increasingly more frequent ${ }^{4}$.

In the literature there is an increase of the consensus in favour of endoscopic septoplasty compared to a conventional approach. However, to date, no author has focused attention on the effectivenes of endoscopic correction, considering all types of septal deformities. More than 20 years ago, Mladina published a systematic classification of septal deformities, precisely defining clinical findings at the nasal septum, and proposing seven different types of deformity ${ }^{56}$.

The purpose of this study is to evaluate the effectivenes of the endoscopic septoplasty for the correction of each of the 7 types of septal deformities according to Mladina's classification.

\section{Materials and methods}

A retrospective chart review was performed in 184 consecutive patients presenting to our Department for endoscopic septoplasty during a 30-month period (February 2012 to August 2014). The patients were 22 females and 37 males with a mean age of 34.9 years, ranging from 18 to 69 . Inclusion criteria were as follows: at least 17 years old, septal deformity with nasal obstruction, persistent symptoms after at least a 4-weeks of therapy including topical nasal steroids in combination or not with antihistamines. Patients with sinonasal malignancy, being in need of nasal surgery other than septoplasty (such as functional endoscopic sinus surgery - FESS -, nasal valve surgery, turbinate surgery etc.), sinonasal infections, sinonasal inflammatory disease, were excluded from the study.

Given the presenting symptoms of patients that may suggest some forms of rhinosinusitis (chronic or acute recurrent forms), all patients were preoperatively evaluated by paranasal sinus computed tomography (CT) $(120 \mathrm{kV}$, $215 \mathrm{~mA} \mathrm{~s}, 1 \mathrm{~mm}$ slice thickness).

Among the 184 patients studied, 125 were excluded for the presence of radiological signs of chronic rhinosinusitis with some anatomical variants as follows: inferior turbinate hypertrophy in $93 \%$ of cases, middle turbinate pneumatisation in $37 \%$ of cases, uncinate process pneumatisation in $8 \%$ and dysventilated sinuses in $60 \%$ of cases.

Therefore, 59 patients (32\%) fulfilled the inclusion criteria for the present study. The most frequent symptoms encountered were nasal obstruction in all cases; facial pain in 27 cases and postnasal drip and headache in 7 cases each. All patients were submitted to allergic evaluations with skin prick tests for inhalants. The degree of septal deviation was calculated using OSIRIX ${ }^{\circledR}$ Software (Pixameo SARL, Bernex, Switzerland, 2003-2014). The angle defined by a line passing through the most deviated point and a line perpendicular to the floor of the nose was calculated to determine the degree of the septal deviation (Fig. 1). Moreover, nasal spaces were directly assessed by nasal endoscopy in all cases.

Using these examinations, we were able to stratify the patient cohort into seven groups based on Mladina's classification of nasal septum deviation (Table I).

All patients included in our study underwent endoscopic septoplasty according to the technique described herein.

Table I. Classification proposed by Mladina.

Type $1 \quad$ Unilateral vertical septal ridge in the valve region that does not reach the valve itself; it does not change the physiologic valve angle (15\%) and therefore usually plays just a mild role in the nasal pathophysiology

Type 2 Unilateral vertical septal ridge in the valve region that touches the nasal valve, thus reducing the physiologic valve angle $(15 \%)$

Type 3 Unilateral vertical ridge that is located more deeply in the nasal cavity, opposite the head of the middle turbinate

Type 4 Bilateral deformity consisting of type 2 on one side and type 3 on the other

Type 5 Almost horizontal septal spur that sticks laterally and deeply into the nasal cavity. The opposite side of the nasal septum is always flat

Type 6 Massive unilateral intermaxillary bone wing with a "gutter" between it and the rest of the septum on this septal side. On the other septal side, there is an anteriorly positioned basal septal crest.

Type $7 \quad$ Very variable combination of the previous types 


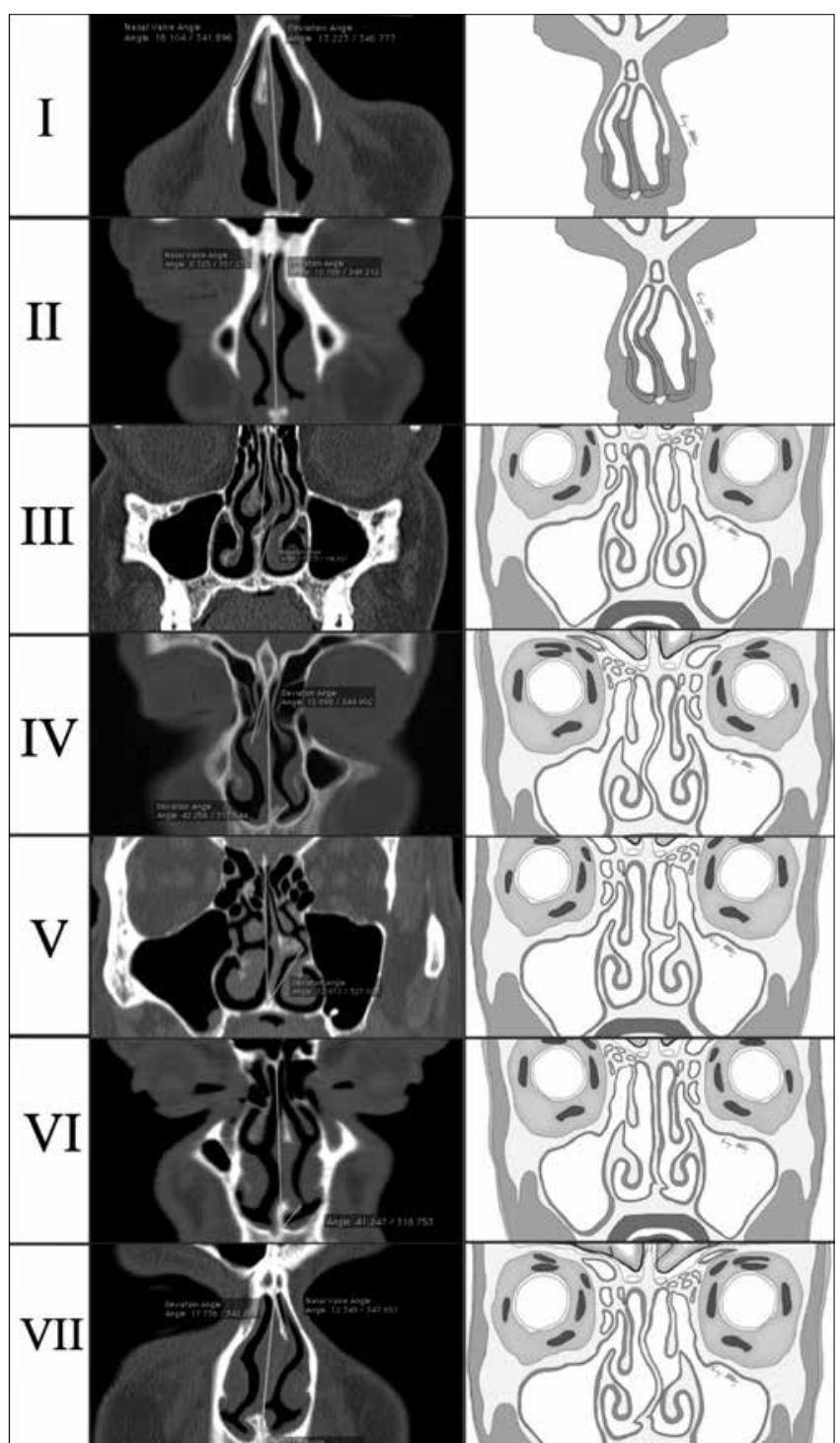

Fig. 1. The seven types of septal deviations proposed by Mladina. In the first column, CT scans processed with OsiriX program are shown; the second column shows schematic illustrations for each deviation.

The procedure was performed under general anaesthesia. The septum was injected with $1 \%$ xylocaine in 1:20,000 epinephrine on the convex side of the septum using a $0^{\circ}$ rigid 4 mm Hopkins Rod Lens endoscope.

In Mladina's type 5 and 6 (Cottle's area IV and V) deformity, a horizontal hemitransfixation incision was made, parallel to the nasal floor on the apex of the spur to expose the most deviated part (Fig. 2a). A submucoperichondral flap was raised using a Cottle elevator under endoscopic visualisation to expose the underlying bone at the most deviated part. To avoid contralateral mucosal damage, careful submucoperichondral dissection on the opposite side was performed using a Cottle elevator. Flaps were elevated superiorly and inferiorly to expose the underlying bony or cartilaginous spur (Fig. 2b). The bony protrusion was removed using a chisel placed on the base of the spur. In Mladina types 2, 3 and 4 deformities (Cottle's area I, II, III), we performed an "endoscopic assisted septoplasty". A vertical incision was made on the concave side of the septum to expose the abnormality at the bony cartilaginous junction. The initial mucoperichondrial flap was elevated using Freer's elevator and nasal speculum. Further elevation was done using $0^{\circ}$ rigid nasal endoscope $(4 \mathrm{~mm})$, held in the left hand, keeping the tip of the endoscope between the mucoperichondrial flap and the septal cartilage (Fig. 2c). The right hand was used for instrumentation. Flap elevation in the correct cleavage plane to minimise bleeding. Exposure was limited to the target area. A subluxated cartilage from the crest was shaved using a No. 15 blade Bard parker knife to resect the excess cartilage inferiorly, without dislocating the vomero-chondral junction (Fig. 2d).

In all cases mucosal flaps were repositioned back in place and is fixed using a silastic stent in order to avoid the mucosal damage during packing removal. Nasal packing was placed in both nasal fossae (Merocel, Medtronic, Mystic, CT, USA) and were removed after 48 hours.

Patients were usually discharged after 48 hours. All pa-

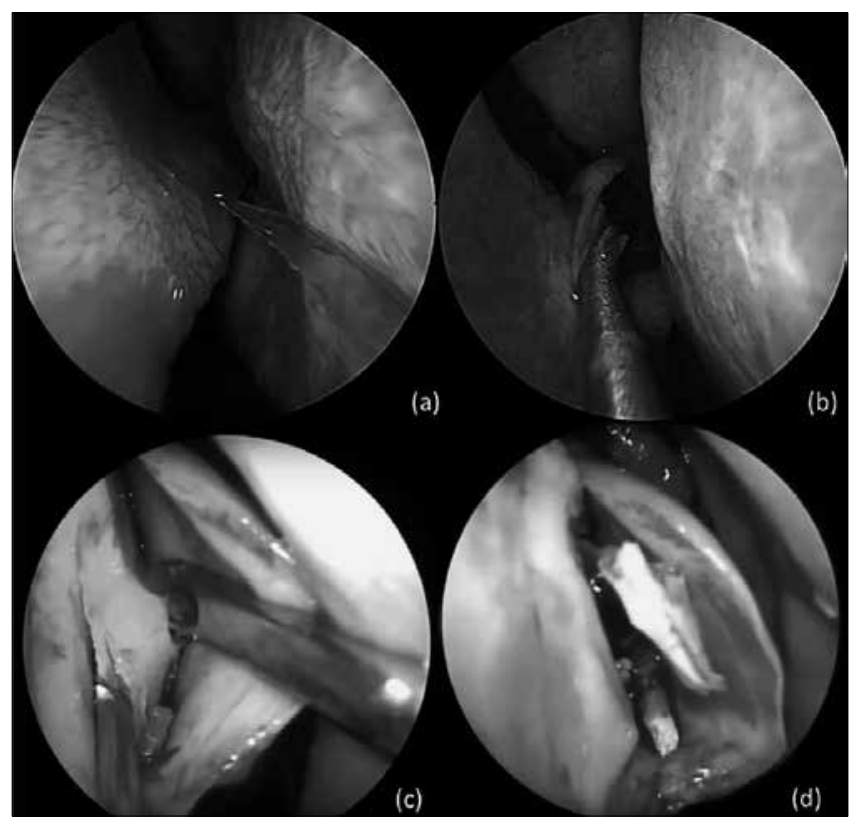

Fig. 2. Intraoperative picture showing: a) horizontal hemitransfixation incision parallel to the nasal floor on the apex of the septal spur; b) flaps elevation to expose the underlying bony or cartilaginous spur; c) $0^{\circ}$ rigid nasal endoscope $(4 \mathrm{~mm})$, inserted between the mucoperichondrial flap and the septal cartilage; d) Cartilage excess resection without dislocating the vomero-chondral junction. 
tients received post-operative antibiotic therapy with oral cephalosporin for one week, saline nasal douching and oral steroids with decreasing dosage.

The main outcome measure used in the study was the NOSE scale (Nasal Obstruction Symptom Evaluation) including a grading score from 0 to 5 (Fig. 3). All patients were asked to complete the NOSE scale one week before surgery and then at 3 and 6 months post-operatively. Nonparametric analysis (Wilcoxon signed rank test) was used to compare baseline and follow-up NOSE scores. $\mathrm{P}$ values $<0.05$ were considered statistically significant. For each deviation, descriptive statistics (mean and standard deviation, significant increase/decrease) were used to assess the possibility to correct each type of deviation.
Nasal endoscopy was performed in all patients at given intervals (15 days, 1 month, 3 months, and 6 months after surgery) to assess possible complications.

\section{Results}

Mean follow-up time was 6.3 months (range 3-14 months). The patient cohort was divided according to the Mladina classification as follows: type 5 was the most frequent deviation observed (23.7\%, 14 cases); type 3 and 6 were also relatively frequent $(20.3 \%, 12$ cases and $18.6 \%, 11$ cases, respectively); types 2 and 1 were observed in equal frequency (13.5\%, 8 cases and 11.8\%, 7 cases, respectively); types 4 and 7 were rare $(6.7 \%, 4$ cases and 5\%, 3 cases, respectively).

Nasal obstruction and Septoplasty Effectiveness Scale (NOSE)

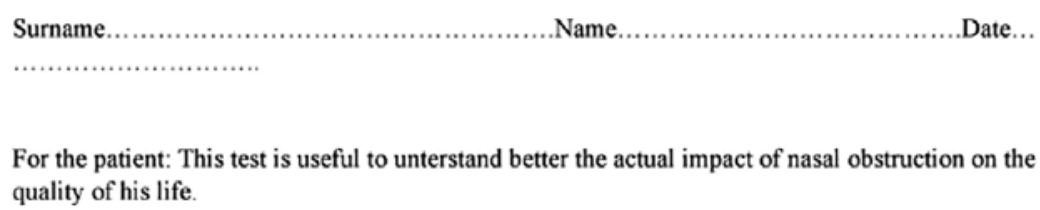
quality of his life

Considering the last month, quantify the impact of each problem listed on its quality of life. Indicate with $\mathrm{X}$ the most correct answer

\begin{tabular}{|c|c|c|c|c|c|}
\hline & Not a problem & Very mild problem & Moderate problem & Fairly bad problem & Severe problem \\
\hline 1. Nasal obstruction and stuffiness & 0 & 1 & 2 & 3 & 4 \\
\hline 2. Nasal obstruction & 0 & 1 & 2 & 3 & 4 \\
\hline 3. Trouble breathing through my nose & 0 & 1 & 2 & 3 & 4 \\
\hline 4. Trouble sleeping & 0 & 1 & 2 & 3 & 4 \\
\hline 5. Unable to get enough air through my nose during exercise & 0 & 1 & 2 & 3 & 4 \\
\hline
\end{tabular}

The test should be repeated after 3 and 6 months after surgery

Fig. 3. The NOSE questionnaire. 
Table II. Our cohort divided according to the Mladina classification. Disease-specific QOL scores (mean and standard deviation) assessed with the NOSE scale at baseline; 3 and 6 months after surgery.

\begin{tabular}{lcccc} 
Deviation & Sample rate (\%) & Baseline & $\mathbf{3}$ months & $\mathbf{6}$ months \\
I & $11.8 \%$ & $14.1 \pm 1.2$ & $12.3 \pm 1.7$ & $12.0 \pm 1.9$ \\
II & $13.5 \%$ & $16.0 \pm 1.0$ & $15.6 \pm 1.0$ & $15.5 \pm 1.0$ \\
III & $20.3 \%$ & $15.0 \pm 0.8$ & $14.5 \pm 0.9$ & $14.1 \pm 0.6$ \\
IV & $6.7 \%$ & $17.8 \pm 0.5$ & $11.0 \pm 3.7$ & $10.2 \pm 3.3$ \\
V & $23.7 \%$ & $18.1 \pm 1.3$ & $0.8 \pm 0.4$ & $0.7 \pm 0.4$ \\
VI & $18.6 \%$ & $17.6 \pm 1.4$ & $7.9 \pm 7.7$ & $7.7 \pm 6.7$ \\
VII & $5 \%$ & $16.6 \pm 1.2$ & $15.3 \pm 0.6$ & $15 \pm 1.0$ \\
\hline
\end{tabular}

The disease-specific QOL scores assessed with the NOSE scale at different intervals of time are detailed in Table II. Compared to baseline, the scores registered at 3 and 6 months after surgery showed significant improvement in nasal symptoms $(\mathrm{p}<0.05)$. The results are shown in Table III.

Significant decreases in nasal obstruction, trouble sleeping, snoring and mouth dryness in the morning were observed between the preoperative period and 3 months after septoplasty. On the other hand, no statistically significant differences between the 3 and 6 month scores were observed.

The analysis of the NOSE scores for each deformity showed a different corrective power depending on the

Table III. Wilcoxon non-parametric test to compare QOL scores registered at baseline, 3 and 6 months after surgery.

\begin{tabular}{|c|c|c|}
\hline Deviation & \multicolumn{2}{|c|}{ P-value } \\
\hline I & $\begin{array}{l}T_{0}-T_{1} \\
T_{1}-T_{2} \\
T_{0}-T_{2}\end{array}$ & $\begin{array}{l}0.015^{\star \star} \\
0.172 \\
0.019^{\star \star}\end{array}$ \\
\hline$\|$ & $\begin{array}{l}T_{0}-T_{1} \\
T_{1}-T_{2} \\
T_{0}-T_{2}\end{array}$ & $\begin{array}{l}0.080 \\
0.998 \\
0.080\end{array}$ \\
\hline |l| & $\begin{array}{l}T_{0}-T_{1} \\
T_{1}-T_{2}^{2} \\
T_{0}-T_{2}\end{array}$ & $\begin{array}{l}0.017^{\star \star} \\
0.082^{\text {a }} \\
0.005^{\star \star \star}\end{array}$ \\
\hline IV & $\begin{array}{l}T_{0}-T_{1} \\
T_{1}-T_{2} \\
T_{0}-T_{2}\end{array}$ & $\begin{array}{l}0.046^{\star \star} \\
0.058 \\
0.027^{\star \star}\end{array}$ \\
\hline V & $\begin{array}{l}T_{0}-T_{1} \\
T_{1}^{2}-T_{2}^{2} \\
T_{0}-T_{2}\end{array}$ & $\begin{array}{l}0.000^{\star \star \star} \\
0.336 \\
0.000^{\star \star \star}\end{array}$ \\
\hline VI & $\begin{array}{l}T_{0}-T_{1} \\
T_{1}-T_{2}^{2} \\
T_{0}-T_{2}\end{array}$ & $\begin{array}{l}0.000^{\star \star \star} \\
0.167^{\star \star \star} \\
0.001^{\star \star \star}\end{array}$ \\
\hline VII & $\begin{array}{l}T_{0}-T_{1} \\
T_{1}-T_{2} \\
T_{0}-T_{2}\end{array}$ & $\begin{array}{l}0.057 \\
0.423 \\
0.038^{\star \star}\end{array}$ \\
\hline
\end{tabular}

$T_{0}$ : baseline; $T_{1}$ : follow up 3 months; $T_{2}$ follow up 6 months.

${ }^{*}:<0,05 ; * * *:<0,01$. type of deviation treated. More in detail, the greater corrective capacity was found for the deviation types 5 and 6 , and then gradually decreased for the septal deviation types 4, 1 and 7, becoming very limited for types 3 and 2. This trend remained unchanged over time (3 month - 6 month follow-up) (Fig. 4).

In our series, 1 septal abscess (Mladina type 4 ) and 1 saddle nose deformity (Mladina type 2) were reported after endoscopic septoplasty. No haematoma, no synechiae, or perforations were observed.

\section{Discussion}

Over the years, many surgical techniques for the correction of septal deformity have become diffuse. The concept of septoplasty was firstly popularised by Killian (1904) ${ }^{7}$ and Freer (1902) ${ }^{8}$ separately more than 100 years ago. In 1947, Cottle defined surgical septoplasty as a treatment to correct nasal airway obstruction, and standardised the technique ${ }^{9}$. This technique has remained largely unchanged up to now. Recently introduced endoscopic endonasal techniques provide better magnification and illumination of the surgical field and can also be used to assist septal surgery ${ }^{11}$.

The application of endoscopic techniques for correction of septal deformities was initially described in 1991 by Stammberger. Since that time, surgeons have performed endoscopic septoplasties not only to treat symptomatic nasal obstruction, but also to improve surgical access to the middle meatus as an adjunct to endoscopic sinus surgery (ESS) ${ }^{10-16}$.

Endoscopic septoplasty is now an attractive alternative to traditional headlight approach for septoplasty.

Bothra et al. showed better results and fewer complications with endoscopic septoplasty compared to conventional approaches, as endoscopy gave better illumination and improved access to high deviations and spurs ${ }^{17}$.

The same opinion in favour of endoscopic septoplasty was expressed later by several authors who compared the 


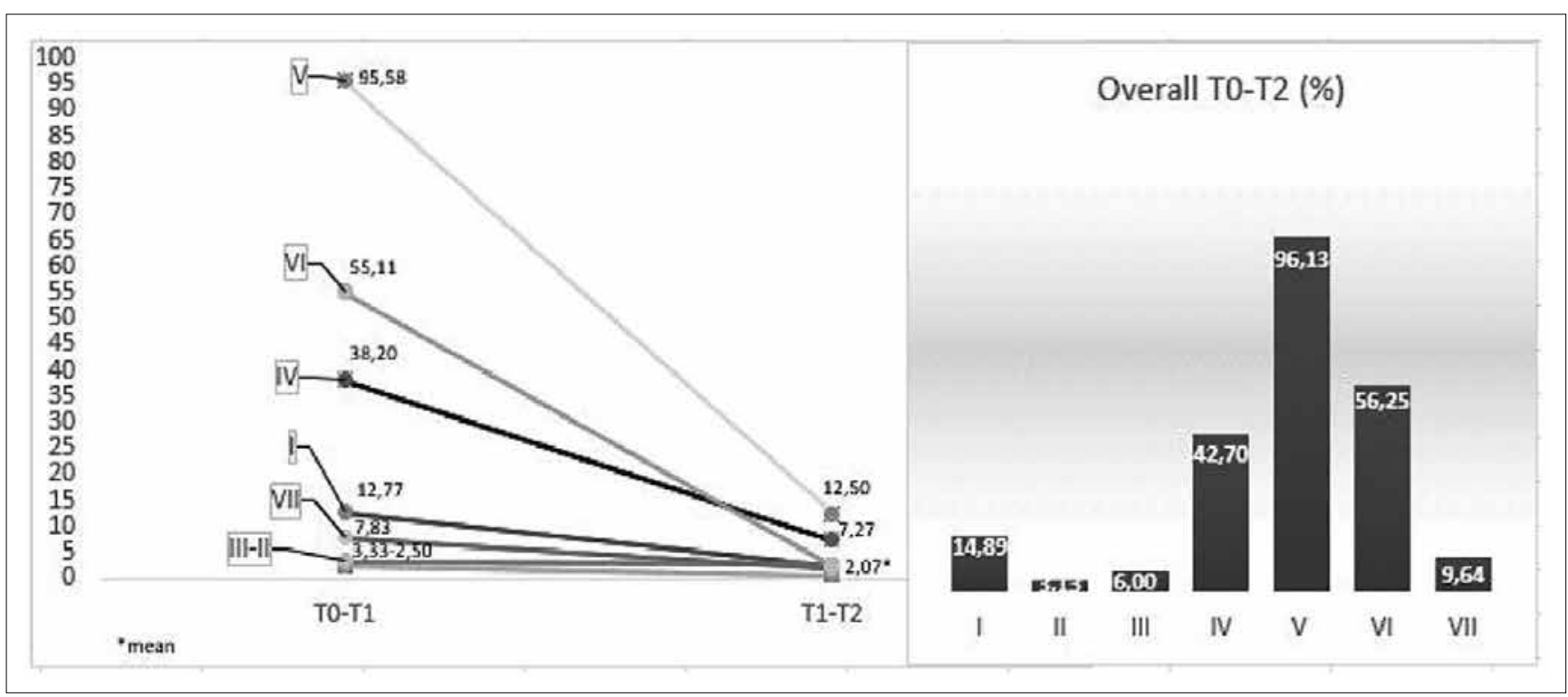

Fig. 4. Percentages decreased for each deviation type at 3 months, 6 months and overall.

two techniques ${ }^{18}$. Gulati et al ${ }^{19}$ found that an endoscopic approach to septoplasty simplifies identification of the pathology due to better illumination, improved accessibility to remote areas and magnification, while allowing for limited incision and elevation of flaps without compromising adequate exposure of the pathological site. Paradis et al. ${ }^{20}$ compared endoscopic vs classic septoplasty. The authors recruited 63 patients with a septal deviation meeting strict inclusion/exclusion criteria and measures outcomes including surgical time, intraoperative complications and pre- and post-operative data from the Nasal Obstruction Symptom Evaluation (NOSE) questionnaire. There were subjective improvements in nasal obstructive symptoms in both groups, but without significant differences between endoscopic and classic septoplasty. However, objective outcome measures, including operative time and intraoperative complications, were favoured by the endoscopic technique. Therefore, considering these findings and the advantages of endoscopy (e.g., improved visualisation of the surgical field, increased precision and enhanced teaching opportunity), the use of an endoscopic approach for septoplasty is suggested over a traditional technique for correction of septal deviation.

While the majority of authors seem to prefer the endoscopic technique, no one has analysed the effectiveness of this procedure in resolving different septal deformity.

To our knowledge, this is the first study that evaluates the corrective capacity of this technique for each type of deviation by analysing pre- and post-operative objective outcomes, as well as subjective outcomes gathered from the validated NOSE questionnaire ${ }^{21-23}$.
Mladina et al. codified a classification for septal deformity based on direct observations of 2589 patients. The authors concluded that almost $90 \%$ of subjects showed 1 of the 7 types of septal deformity described ${ }^{624}$. We divided our cohort based on this simple and effective classification. By direct endoscopic visualisation and data processing of coronal CT scans, it was easily possible to stratify our sample into each of the seven types described by Mladina et al. ${ }^{6}$.

For those who deal with functional nasal surgery, evaluation of the nasal airflow perception is the most difficult parameter to study. Nasal breathing is a complex function of the nose that may be influenced by various conditions such as humidity, nasal resistance and contact of inspiration air with nasal surfaces. Stewart et al. in 2004 completed the validation of a disease-specific instrument to assess nasal obstruction: the NOSE scale ${ }^{25}$. According to Kahveci et al., who found the NOSE scale a very efficient tool to evaluate outcomes of septoplasty, we adopted this tool to assess the effectiveness of endoscopic septoplasty in different types deviations, comparing outcomes observed preoperatively and at 3 and 6 months post-operatively ${ }^{21}$. Generally, turbinate surgery was not accepted as an exclusion criterion when functional outcomes of septoplasty were evaluated 222526 . However, we preferred to include only patients with septal deviation without any other confounding factors (e.g. inferior turbinate hypertrophy) to evaluate the efficiency of septoplasty.

Data analysis from the NOSE score showed a marked improvement in airflow perception in all patients treated. No 
significant differences were appreciated by comparing the NOSE score at 3 months and 6 months after surgery. According to Skitarelic et al., these findings showed that endoscopic septoplasty is an effective procedure with stable results over time ${ }^{19}$.

What we consider very interesting is that the analysis of the NOSE score for individual septal deformity highlighted a different efficacy of the surgical procedure. In particular, the corrective power seems to be greater for deviation types 5 and 6 , gradually decreasing in types 4,1 and 7 and becoming minimal for types 3 and 2 . As already shown by Gupta et al., endoscopic vision allows excellent lighting of the septum in the rear portion (Cottle's area IV, V) and faciltates correction of all deviations in this area. Because deviations type 5 and 6 are located mainly in the posterior areas, this could explain the increased corrective power obtained for these deviations in our sample 2728 .

Nayak et al. reported that about $10 \%$ of cases with anterior septal deformity had persistent septal deviation after endoscopic septoplasty. In the same way, we have found greater difficulty in performing endoscopic procedure for deviations in this area (Cottle 's area I, II, III) ${ }^{11} 27$.

In these areas, it is difficult to obtain a good endoscopic vision for the lack of support for the endoscope. Moreover, the elastic recoil of the cartilage requires detaching a large portion of the septum and to release it in the caudal portion. Therefore, significant bleeding requiring too frequent cleaning of the endoscope's tip render the procedure difficult in this area. We believe that this may explain the reduced corrective capacity of the endoscopic septoplasty for type 2, 3 and 7 deformities.

\section{Conclusions}

This study has shown that the corrective power of endoscopic septoplasty is different according to the type of deviation. Even if endoscopic septoplasty may be considered as a reliable alternative to traditional techniques, it is essential to properly identify the type of deformity preoperatively in order to select the adequate surgical strategy. Long term follow-up and larger series are necessary to more accurately assess the indications and limitations of endoscopic-assisted septoplasty in all types of deviation.

\section{References}

1 Pannu KK, Chadha, Kaur IP. Evaluation of benefits of nasal septal surgery on nasal symptoms and general health. Indian J Otolaryngol Head Neck Surg 2009;61:59-65.

2 Ahmadian A, Fathi Kazerooni A, Mohagheghi S, et al. A region-based anatomical landmark configuration for sinus surgery using image guided navigation system: a phantomstudy. J Craniomaxillofac Surg 2014;42:816-24.

3 Chang M, Lee H, Park M, et al. Long-term outcomes of endoscopic endonasal conjunctivodacryocystorhinostomy with Jones tube placement: a thirteen-year experience. J Craniomaxillofac Surg 2015;43:7-10.

4 Lanza DC, Kennedy DW, Zinreich SJ. Nasal endoscopic and its surgical applications. In: Lee KJ. ed. Essential otolaryngology, head and neck surgery. New York (NY): Medical Examination Publisching Co.; 1991. p. 373-87.

5 Mladina $\mathrm{R}$. The role of maxillar morphology in the development of pathological septal deformities. Rhinology 1987;25:199-205.

6 Mladina R, Cujić E, Subarić M, et al. Nasal septal deformities in ear, nose, and throat patients: an international study. Am J Otolaryngol 2008;29:75-82.

7 Killian G. Die submucose Fensterresektion der Nasenscheidewand. Archivies fur Laryngologie und Rhinologie 1904;16:363.

8 Freer O. The correction of nasal septum with a minimum of traumatism. JAMA 1902;38:636.

9 Jammet P, Souyris F, Klersy F, et al. The value of Cottle's technic for esthetic and functional correction of the nose. Ann Chir Plast Esthet 1989;34:38-41.

10 Nayak DR, Balakrishnan R, Murty KD, et al. Endoscopicseptoturbinoplasty: our update series. Indian J Otolaryngol Head Neck Surg 2002;54:20-4.

11 Lanza DC, Moran DT, Doty RL, et al. Endoscopic human olfactory biopsy technique: a preliminary report. Laryngoscope 1993;103:815-9.

12 Giles WC, Gross CW, Abram AC, et al. Endoscopic septoplasty. Laryngoscope 1994;104:1507-9.

13 Cantrell H. Limited septoplasty for endoscopic sinus surgery. Otolaryngol Head Neck Surg. 1997;116:274-7.

14 Yanagisawa E, Joe J. Endoscopic septoplasty. Ear Nose Throat J 1997;76:622-3.

15 Toffel PH. Depth of field image video enhancement for endoscopic sinus surgery. Ear Nose Throat J 1998;77:549-51.

16 Hwang PH, McLaughlin RB, Lanza DC, et al. Endoscopic septoplasty: indications, technique, and results. Otolaryngol Head Neck Surg 1999;120:678-82.

17 Bothra R, Mathur NN. Comparative evaluation of conventional versus endoscopic septoplasty for limited septal deviation and spur. J Laryngol Otol 2009;123:737-41.

18 Skitarelic NB, Vukovic K, Skitarelic NP. Comparative evaluation of conventional versus endoscopic septoplasty for limited septal deviation and spur. J Laryngol Otol 2009;123:939-40.

19 Gulati SP, Wadhera R, Ahuja N, et al. Comparative evaluation of endoscopic with conventional septoplasty. Indian $\mathbf{J}$ Otolaryngol Head Neck Surg 2009;61:27-9.

20 Paradis J, Rotenberg BW. Open versus endoscopic septoplasty: a single-blinded, randomized, controlled trial. J Otolaryngol Head Neck Surg 2011;40(Suppl 1):S28-33. 
21 Kahveci OK, Miman MC, Yucel A, et al. The efficiency of Nose Obstruction Symptom Evaluation (NOSE) scale on patients with nasal septal deviation. Auris Nasus Laryn 2012;39:275-9.

22 Gandomi B, Bayat A, Kazemei T. Outcomes of septoplasty in young adults: the nasal obstruction septoplasty effectiveness study. Am J Otolaryngol 2010;31:189-92.

23 André RF, Vuyk HD, Ahmed A, et al. Correlation between subjective and objective evaluation of the nasal airway. A systematic review of the highest level of evidence. Clin Otolaryngol 2009;34:518-25.

24 Janiszewska-Olszowska J, Gawrych E, Wędrychowska-Szulc $\mathrm{B}$, et al. Effect of primary correction of nasal septal deform- ity in complete unilateral cleft lip and palate on the craniofacial morphology. J Craniomaxillofac Surg 2013;41:468-72.

25 Stewart MG, Witsell DL, Smith TL, et al. Development and validation of the Nasal Obstruction Symptom Evaluation (NOSE) scale. Otolaryngol Head Neck Surg 2004;130:157-63.

26 Uppal S, Mistry H, Nadig S, et al. Evaluation of patient benefit from nasal septal surgery for nasal obstruction. Auris Nasus Larynx 2005;32:129-37.

27 Cottle MH, Loring RM, Fischer GG, et al. The maxilla-premaxilla approach to extensive nasal septum surgery. AMA Arch Otolaryngol 1958;68:301-13.

28 Gupta N. Endoscopic septoplasty. Indian J Otolaryngol Head Neck Surg 2005;57:240-3.

Received: January 27, 2016 - Accepted: June 6, 2017

Address for correspondence: Giovanni Salzano, Department of Maxillofacial Surgery, University of Naples Federico II, via Pansini 5, 80131 Naples, Italy. Tel. +39 081 7462176. E-mail: giovannisalzanomd@gmail.com 